\title{
Trends in the incidence of dementia: design and methods in the Alzheimer Cohorts Consortium
}

\author{
Lori B. Chibnik ${ }^{1,2}$ - Frank J. Wolters ${ }^{1,3} \cdot$ Kristoffer Bäckman $^{5}$ - Alexa Beiser ${ }^{6,7,8}$ • \\ Claudine Berr' ${ }^{9}$ Joshua C. Bis ${ }^{10}$ - Eric Boerwinkle ${ }^{12}$ - Daniel Bos ${ }^{1,3,4}$. \\ Carol Brayne $^{13} \cdot$ Jean-Francois Dartigues $^{14} \cdot$ Sirwan K. L. Darweesh $^{1,3}$. \\ Stephanie Debette ${ }^{14,15} \cdot K^{-}$endra L. Davis-Plourde ${ }^{7,8} \cdot$ Carole Dufouil $^{14}$. \\ Myriam Fornage $^{16} \cdot$ Leslie Grasset $^{14}$ - Vilmundur Gudnason ${ }^{17,18}$ - Christoforos Hadjichrysanthou ${ }^{19}$. \\ Catherine Helmer $^{14}$ - M. Arfan Ikram ${ }^{3}$ M. Kamran Ikram ${ }^{3}$ - Silke Kern ${ }^{5}$. \\ Lewis H. Kuller ${ }^{20}$ - Lenore Launer ${ }^{21}$ - Oscar L. Lopez ${ }^{24}$ - Fiona Matthews ${ }^{22}$. \\ Osorio Meirelles $^{21} \cdot$ Thomas Mosley $^{23} \cdot$ Alison Ower $^{19} \cdot$ Bruce M. Psaty $^{10,11}$. \\ Claudia L. Satizabal $^{6} \cdot$ Sudha Seshadri $^{6} \cdot$ Ingmar Skoog $^{5} \cdot$ Blossom C. M. Stephan $^{22}$. \\ Christophe Tzourio $^{14}$ - Reem Waziry ${ }^{1} \cdot$ Mei Mei Wong ${ }^{19} \cdot$ Anna Zettergren $^{5}$. \\ Albert Hofman ${ }^{1,3}$
}

Received: 7 August 2017 / Accepted: 6 October 2017/Published online: 23 October 2017

(C) The Author(s) 2017. This article is an open access publication

Abstract Several studies have reported a decline in incidence of dementia which may have large implications for the projected burden of disease, and provide important

Drs Chibnik and Wolters have contributed equally to this manuscript.

Albert Hofman

ahofman@hsph.harvard.edu

1 Department of Epidemiology, Harvard T.H. Chan School of Public Health, 677 Huntington Ave., Kresge 905, Boston, MA 02115, USA

2 Channing Division of Network Medicine, Brigham and Women's Hospital, Boston, MA, USA

3 Department of Epidemiology, Erasmus MC, Rotterdam, The Netherlands

4 Department of Radiology and Nuclear Medicine, Erasmus MC, Rotterdam, The Netherlands

5 Institute of Neuroscience and Physiology, Sahlgrenska Academy, University of Gothenburg, Gothenburg, Sweden

6 Boston University School of Medicine, Boston, MA, USA

7 The Framingham Heart Study, Framingham, MA, USA

8 Department of Biostatistics, Boston University School of Public Health, Boston, MA, USA

9 INSERM, Univ Montpellier, Neuropsychiatry: Epidemiological and Clinical Research, Montpellier, France

10 Cardiovascular Health Research Unit, Department of Medicine, University of Washington, Seattle, WA, USA

11 Kaiser Permanente Washington Health Research Institute, Seattle, WA, USA guidance to preventive efforts. However, reports are conflicting or inconclusive with regard to the impact of gender and education with underlying causes of a presumed declining trend remaining largely unidentified. The Alzheimer Cohorts Consortium aggregates data from nine international population-based cohorts to determine

12 University of Texas School of Public Health, Houston, TX, USA

13 University of Cambridge, Cambridge, UK

14 Univ. Bordeaux, Inserm, Bordeaux Population Health Research Center, UMR1219, Bordeaux F-33000, France

15 Department of Neurology, Memory Clinic, Bordeaux University Hospital, Bordeaux, France

16 University of Texas Health Science Center at Houston McGovern Medical School, Houston, TX, USA

17 Icelandic Heart Association, Kópavogur, Iceland

18 Faculty of Medicine, University of Iceland, Reykjavík, Iceland

19 Department of Infectious Disease Epidemiology, School of Public Health, Imperial College London, London, UK

20 Department of Epidemiology, Graduate School of Public Health, University of Pittsburgh, Pittsburgh, PA, USA

21 Laboratory of Epidemiology and Population Sciences, National Institute on Aging, Bethesda, MD, USA

22 Newcastle University, Newcastle upon Tyne, UK

23 University of Mississippi Medical Center, Jackson, MS, USA

24 Departments of Neurology \& Psychiatry, University of Pittsburgh, Pittsburgh, PA, USA 
changes in the incidence of dementia since 1990 . We will employ Poisson regression models to calculate incidence rates in each cohort and Cox proportional hazard regression to compare 5-year cumulative hazards across study-specific epochs. Finally, we will meta-analyse changes per decade across cohorts, and repeat all analysis stratified by sex, education and APOE genotype. In all cohorts combined, there are data on almost 69,000 people at risk of dementia with the range of follow-up years between 2 and 27. The average age at baseline is similar across cohorts ranging between 72 and 77 . Uniting a wide range of diseasespecific and methodological expertise in research teams, the first analyses within the Alzheimer Cohorts Consortium are underway to tackle outstanding challenges in the assessment of time-trends in dementia occurrence.

Keywords Alzheimer disease - Cohort analysis . Epidemiology $\cdot$ Consortium

\section{Introduction}

It is estimated that approximately 47 million people are currently living with dementia, making it a leading cause of dependence and disability worldwide [1]. Because of a rapidly aging population, this number is predicted to have nearly doubled by 2040 [2]. Consequently the social and economic burdens of dementia are expected to substantially increase [3]. Yet, the projected burden of disease could be significantly lower if improvements in life conditions and health care over the last decades have had a beneficial effect on reducing risk of dementia. Indeed, recent studies in North America and Europe have reported a decline in the incidence of dementia over the last 20 years, up to $20 \%$ reduction per decade [4-8]. However, the underlying causes have not been determined, and discrepancies in described trends between sexes, and across different ethnicities and levels of education warrant further exploration $[9,10]$.

Valid assessment of time trends in the incidence of a disease calls for careful monitoring of it within the general population, in a consistent manner over a prolonged period of time. Population-based cohort studies are generally designed to establish determinants of disease, using consistent methodology throughout the course of data collection. The wide range of routinely collected data within these studies allows for exploration of effect modifiers (e.g. genotype or sex), as well as various potential underlying causes, such as changes in cardiovascular risk management, comorbidity (e.g. stroke), and level of education. Worldwide, however, only a limited number of studies exist, that are carried out in unselected populations and provide the infrastructure and decade-long follow-up duration necessary to determine trends in dementia incidence. Power and precision of these individual studies are not always sufficient to answer the research questions outlined above. We therefore aim to jointly analyse available long-term population-based data seeking confirmation for any time trends in dementia occurrence and importantly identify determinants of such trends. The results will have important implications for informing public health policy focused on dementia reduction.

\section{Materials and methods}

\section{The Alzheimer Cohorts Consortium}

The Alzheimer Cohorts Consortium is a collaboration of nine prospective cohorts studies from the United States and Europe including: the Age, Gene/Environment Susceptibility (AGES)-Reykjavik Study, the Atherosclerosis Risk in Communities (ARIC) study, the Cardiovascular Health Study (CHS), the Cognitive Function and Ageing Studies (CFAS), the Framingham Heart Study (FHS), the Gothenburg population studies, the Personnes Agées QUID (PAQUID) study, the Rotterdam Study, and the Three-City Study (3C). All cohorts are population-based and comprise of prospectively collected data on dementia (and in most studies information on clinical subtypes), in addition to genotyping, and extensive (cardiovascular) phenotyping.

\section{Description of cohorts}

A summary of the key characteristics of each cohort are presented in Table 1. Across the cohorts there are more than 70,000 individuals of whom around 6300 have developed dementia to date. Briefly, the AGES-Reykjavik Study represents a sample drawn from the population-based Reykjavik Study [11]. The original Reykjavik Study comprised a random sample of 30,795 men and women born between 1907 and 1935 and living in Reykjavik in 1967. Between 1967 and 1996, six examinations were conducted in six sub-cohorts, and 5764 survivors of the original cohort were re-examined for the AGES-Reykjavik study between 2002 and 2006. The ARIC study is a population-based prospective cohort study of cardiovascular disease and its risk factors [12]. Chosen by probability sampling from four U.S. communities including WinstonSalem (NC), Jackson (MS), Minneapolis (MN), and Baltimore (MD), the study included 15,792 individuals aged 45-64 years at study baseline in 1987-1989. Participants completed four clinic examinations, conducted 3 years apart, up till 1998, and undergo annual follow-up for clinical events. Between 2011 and 2013, all surviving ARIC participants were invited to a 5th visit (ARIC 
Table 1 Description of the cohorts included in the Alzheimer Cohorts Consortium

\begin{tabular}{|c|c|c|c|c|c|c|c|c|c|}
\hline Study & $\begin{array}{l}\text { AGES- } \\
\text { Reykjavik }\end{array}$ & $\begin{array}{l}\text { ARIC } \\
\text { NCS }\end{array}$ & $\begin{array}{l}\text { CFAS } \\
\text { I/II }\end{array}$ & CHS & $\begin{array}{l}\text { Framingham } \\
\text { Heart Study }\end{array}$ & $\begin{array}{l}\text { Gothenburg } \\
\text { studies }\end{array}$ & PAQUID & $\begin{array}{l}\text { Rotterdam } \\
\text { Study }\end{array}$ & $\begin{array}{l}\text { Three-City } \\
\text { Study }\end{array}$ \\
\hline Country & Iceland & USA & UK & USA & USA & Sweden & France & Netherlands & France \\
\hline Study baseline & 2002 & 2011-2013 & $\begin{array}{l}1991 / \\
2008\end{array}$ & 1991 & 1990 & 1990 & 1988 & 1990 & 1999 \\
\hline Family-based & No & No & No & No & Yes & No & No & No & No \\
\hline Study sites & 1 & 4 & $3 / 3$ & 4 & 1 & 1 & 1 & 1 & 3 \\
\hline $\begin{array}{l}\text { Dementia } \\
\text { follow-up } \\
\text { (years) }\end{array}$ & 14 & $5^{\mathrm{a}}$ & $2 / 2$ & 18 & 25 & 25 & 27 & 25 & 16 \\
\hline $\begin{array}{l}\text { Diagnosis of } \\
\text { dementia }\end{array}$ & DSM-IV & DSM-V & $\begin{array}{l}\text { DSM- } \\
\text { IIIR }\end{array}$ & DSM-IV & DSM-IV & DSM-IIIR & DSM-IIIR & DSM-IIIR & DSM-IV \\
\hline Diagnosis of $\mathrm{AD}$ & $\begin{array}{l}\text { NINCDS- } \\
\text { ADRDA }\end{array}$ & NIA-AA & N/A & $\begin{array}{r}\text { NINCDS- } \\
\text { ADRDA }\end{array}$ & $\begin{array}{l}\text { NINCDS- } \\
\text { ADRDA }\end{array}$ & $\begin{array}{r}\text { NINCDS- } \\
\text { ADRDA }\end{array}$ & $\begin{array}{l}\text { NINCDS- } \\
\text { ADRDA }\end{array}$ & $\begin{array}{l}\text { NINCDS- } \\
\text { ADRDA }\end{array}$ & $\begin{array}{l}\text { NINCDS- } \\
\text { ADRDA }\end{array}$ \\
\hline
\end{tabular}

AGES Age, Gene/Environment Susceptibility, ARIC-NCS Atherosclerosis Risk in Communities Neurocognitive Study, CFAS Cognitive Function and Ageing Studies, CHS Cardiovascular Health Study, PAQUID Personnes Agées QUID, AD Alzheimer's disease, N/A not available ${ }^{a}$ Efforts to work-up recent incident dementia cases are ongoing as of January 2017

Neurocognitive Study (ARIC-NCS), when a comprehensive dementia assessment was performed. The CHS is a population-based cohort study of risk factors for cardiovascular disease in adults aged 65 years and older, recruited in 1989-1990 from random samples of the Medicare lists in four U.S. field centers, namely Sacramento (CA), Hagerstown (MD), Winston-Salem (NC), and Pittsburgh (PA) [13] The original predominantly white cohort of 5888 persons was expanded by enrolment of 687 African-Americans in 1992-1993. Participants completed standardized clinical examinations and questionnaires at study baseline and at annual follow-up visits until 1999 . Ongoing follow-up for clinical events occurs by phone every 6 months thereafter. The CFAS comprise two separate population-based studies in three sites from the original Medical Resource Council CFAS (Cambridgeshire, Newcastle and Nottingham), conducted 20 years apart in the UK [5]. The samples includes individuals aged 65 years and over regardless of residential status (i.e. persons living in the community as well as institutions). The first study, CFAS I, recruited in 1990-1993 $(\mathrm{N}=7635)$ with a 2-year follow-up in of $20 \%$ of participants $(\mathrm{n}=900)$ in 1993-1995. A second, comparison study, CFAS II, was initiated two decades later, between 2008 and $2011(\mathrm{~N}=7796)$ with a 2-year follow-up screening $(\mathrm{n}=5288)$ in 2011-2013. Identical methods were used in CFAS I and CFAS II with the exception of a two-stage enrolment (separate screening and assessment interview) utilized in CFAS I and a one-stage enrolment for CFAS II (single screening and assessment interview) [14]. The FHS began in 1948 with the recruitment of an original cohort of 5209 men and women who were aged 28-62 at study entry [15]. In 1971, a second generation of study participants, including 5124 children and spouses of children of the original cohort were enrolled [16]. Enrolment of the third generation cohort of 4095 children of offspring cohort participants began in 2002 [17]. Clinic follow-up examinations take place approximately every two year for the original cohort and approximately every 4 years for the Offspring and Third Generation cohorts. In addition, the cohorts are under continuous surveillance for disease endpoints, such as myocardial infarction, stroke, and dementia. The Gothenburg population studies consist of data from four studies which recruited individuals representative of the Swedish population [18]. These include Kvinnoundersökningen (KVUS), a study of 1462 women aged 38-60 who have been followed since 1968; the H70 study, which includes representative samples of 70-yearolds born 1906-1907 ( $\mathrm{N}=414)$, recruited 1976-1977, and followed until death, and $1930(\mathrm{~N}=522)$, recruited 2000-2001 and followed until now, the H85 study, which includes samples of 85-year-olds born 1901-1902 $(\mathrm{N}=494)$, first examined in 1986 and followed until death, and 1923-1924 ( $\mathrm{N}=571)$, first examined in 2008-2009 and followed until age 90; and the 95-plus study that started in 1996 and by 2012 had recruited a total of 950 individuals. The PAQUID cohort is a populationbased study in the southwest of France of 3777 individuals aged 65 years or older recruited in 1988 [19]. There have been nine waves of data collection at 1, 3, 5, 8, 10, 13, 15, $17,20,23,25$, and 27 years after the baseline assessment. The $R S$ is a prospective population-based cohort study comprising 14,926 subjects aged 45 years or older [20]. Baseline data of 7983 participants were collected between 
1990 and 1993, with subsequent cohort expansions in 2000 (3011 individuals) and 2006 (3236 individuals). Participants have been examined once every 4 years. In addition, the entire cohort is continuously under surveillance for disease outcomes through linkage of electronic medical records with the study database. The $3 C$ is a longitudinal population-based study of the relation between vascular diseases and dementia in persons aged 65 years and older [21]. Between 1999 and 2001, a total of 9294 non-institutionalized persons were recruited from the electoral rolls of three French cities: Bordeaux (South-West), Dijon (North-East) and Montpellier (South-East). Participants have been re-examined every 2 years.

\section{Ethics}

All participating studies have ethical approval, and all subjects (or their nominated representative) provided written informed consent.

\section{Dementia assessment}

The primary outcome is all-cause dementia and this is assessed in all cohorts (Table 1). The secondary outcome is diagnoses of Alzheimer's disease (AD), the most common clinical subtype. Methods for dementia diagnosis varied between cohorts, but are consistently applied in each cohort throughout the study period. An exception is CHS, in which participants are re-examined more frequently from 2002 onwards (i.e. annually) compared to before diagnosis of dementia and is based on change in cognition and function from previous visits.

\section{Defining epochs}

One option for assessing trend over time is to define units of time based on the same calendar years across cohorts. This method makes it easy to combine results across cohorts, but ignores the fact that each study has its own pattern of examination cycles and therefore risks bringing in more biases based on study design. To avoid this, we choose to define units of time, or epochs, specific to each study based on each interview wave. This allows us to take full advantage of all available data in each study, maximize the person-years available and also, by using the median time since beginning of first epoch (as described in more detail below in the statistical analysis section), we can compare trends over the years across all the cohorts. Requirements for defining an epoch are: (1) start at or close to an examination cycle, (2) non-overlapping with previous or subsequent epoch, and (3) at least 5 years in length. Participants need to be 60 years or over, and free of dementia at the start of the epoch to be included. All cohorts have follow-up for at least two epochs, except for AGES, in which only a baseline epoch has sufficient follow-up.

\section{Statistical analysis}

All analyses are currently being performed in individual cohorts and results will be meta-analysed when appropriate. Demographic characteristics of each cohort are summarized using means with standard deviation (SD) for continuous measures and frequencies for categorical measures. The calendar time-window of the present analyses is restricted to 1990-2015 to allow for assessment of incidence rates and time trends across the same time-period in all cohorts.

Five-year incidence rates (IRs) with $95 \%$ confidence intervals (CI) are being calculated using age-adjusted Poisson regression models. Groups are first stratified by 5-year age-groups and then additionally by sex. IRs are reported for the middle age within each age group, e.g. 62.5 for the (60-65) age group, 67.5 for the (65-70) age group, etcetera. A participant is included in a particular age group if they were dementia-free at start of the age group category. Since all the cohorts have repeated visits with participants, when data was available, a single person could contribute to IRs of multiple age groups. To account for this, we employ robust sandwich estimators to calculate the 95\% CI around the IRs.

Five-year cumulative hazards and hazard ratios are being assessed individually in each cohort and not combined across studies because of differing timing of examinations. Non-overlapping epochs are defined based on examination cycles and are specific to each cohort. Five-year cumulative hazard and hazard ratios (HRs) are being calculated using a Cox proportional hazard regression model and adjusted for age and sex in non-stratified models using a robust sandwich estimator for covariance structure [22]. Participants who did not experience a dementia diagnosis are censored at the last date they were known to be free of dementia, or 5 years after the beginning of the epoch, whichever was sooner. Hazard ratios are being computed for each epoch as compared to the first epoch followed by trend per decade. We do this by assigning to each epoch an index value equal to median time in years since the beginning of the first epoch. For example, if epoch 1 was 1995-1999 and epoch 2 was 2000-2005 then the index variable would be 2.5 and 7.5 respectively. The index variable is then used in the Cox proportional hazard regression to assess a linear change in hazard of dementia over the epochs or linear trend. To ensure the analyses are identical across cohorts, statistical code using both SPSS and SAS was developed and tested using the Rotterdam 
Study dataset to ensure results matched between statistical software programs and then provided to each cohort for analyses. All analyses are currently being performed using either SPSS version 23.0 (IBM Corp, Armonk, NY, USA) or SAS 9.4 (Cary, NC, USA).

\section{Results}

Descriptions of all cohorts are summarized in Table 1 . In all cohorts combined there is data on almost 69,000 people at risk of dementia with the range of follow-up years between 2 and 27. The average age at baseline is similar across cohorts ranging between 72 and 77 (Table 2). Each cohort is made up of $>50 \%$ females, ranging from $56.8 \%$ in FHS to $76.3 \%$ in the Gothenburg studies (Table 2). All cohorts collect information on incident dementia and all but one cohort (CFAS I/II) also collecting information on incident AD.

\section{Discussion}

Several of the cohorts within the Alzheimer Cohorts Consortium have previously published data on time trends in the prevalence and incidence of dementia $[4,5,7,8]$. In this collaboration, we aim to reproduce these findings using consistent analytical techniques, and harmonise results across the individual cohort studies to identify underlying trends and investigate subgroups of interest (e.g. stratification by gender) and effect modifiers. The close collaboration between cohorts in the consortium, along with the high-quality study design and data collection methods facilitate these analyses of incidence trends over the past three decades.

\section{Cohort enrolment, resampling, and survival bias}

Most cohorts contributing data to these analyses use a closed-cohort design with single enrolment, while two of the cohorts, FHS and the Rotterdam Study, are expanded during the study period, including additional individuals from the source population and one set of cohorts, CFAS I and CFAS II is composed of two comparison cohorts each with a follow-up assessment. Single enrolment in closed cohorts will limit the number of comparable individuals within the same age range, as the cohort on average becomes older over time. We intend to utilize the full potential of this collaboration by including all available data, i.e. expansion cohorts as well as the originally defined cohorts. On a participant level, we allow a single participant to be included in multiple epochs as long as they are free of dementia at the start of the epoch. This can lead to underestimation of the standard error and thus we utilize robust standard error estimates. Restricting non-demented participants to only a single epoch, such as the epoch of their first examination, would deplete the number of participants susceptible to dementia over time. This would mean that individuals at high risk would be underrepresented at later time points. Such selection bias could result in underestimation of the incidence rates and cumulative hazards in more recent years. Conversely, mortality rates have dropped substantially over the past decades, and the increase in life-expectancy renders more people susceptible

Table 2 Demographics of the cohorts included in the Alzheimer Cohorts Consortium

\begin{tabular}{|c|c|c|c|c|c|c|c|c|c|}
\hline Study & $\begin{array}{l}\text { AGES- } \\
\text { Reykjavik }\end{array}$ & $\begin{array}{l}\text { ARIC } \\
\text { NCS }\end{array}$ & $\begin{array}{l}\text { CFAS } \\
\mathrm{I} / \mathrm{II}\end{array}$ & CHS & $\begin{array}{l}\text { Framingham Heart } \\
\text { Study }\end{array}$ & $\begin{array}{l}\text { Gothenburg } \\
\text { studies }\end{array}$ & PAQUID & $\begin{array}{l}\text { Rotterdam } \\
\text { Study }\end{array}$ & $\begin{array}{l}\text { Three-City } \\
\text { Study }\end{array}$ \\
\hline $\begin{array}{l}\text { At risk of } \\
\text { dementia }\end{array}$ & 5722 & 6538 & $\begin{array}{l}7635 / \\
7762\end{array}$ & 2798 & 8586 & 3024 & 2997 & 11,044 & 8250 \\
\hline Mean age (years) & 77.0 & 75.8 & $\begin{array}{l}75.0 / \\
76.4\end{array}$ & 74.7 & 72.1 & 77.3 & 75.3 & 72.0 & 74.0 \\
\hline Women $(\%)$ & 57.7 & 58.8 & $\begin{array}{l}61.6 / \\
56.1\end{array}$ & 59.1 & 56.8 & 76.3 & 58.0 & 58.5 & 61.3 \\
\hline $\begin{array}{l}\text { Caucasian } \\
\text { ethnicity }(\%)\end{array}$ & 100 & 76.1 & $\begin{array}{l}99.1 / \\
97.2\end{array}$ & 89.5 & 100 & 100 & $\mathrm{NC}^{\mathrm{b}}$ & 98.0 & 100 \\
\hline $\begin{array}{l}\text { Incident } \\
\text { dementia }^{a}\end{array}$ & 250 & 344 & $\begin{array}{l}250 / \\
250\end{array}$ & 680 & 800 & 700 & 940 & 1400 & 950 \\
\hline Incident $\mathrm{AD}^{\mathrm{a}}$ & 150 & 72 & N/A & 590 & 510 & 300 & 730 & 1100 & 650 \\
\hline
\end{tabular}

AGES Age, Gene/Environment Susceptibility, ARIC-NCS Atherosclerosis Risk in Communities Neurocognitive Study, CFAS Cognitive Function and Ageing Studies, CHS Cardiovascular Health Study, PAQUID Personnes Agées QUID, AD Alzheimer's disease, N/A Not Available

${ }^{a}$ Approximation of total number of individuals with dementia per cohort at time of press

${ }^{\mathrm{b}}$ Not collected 
to dementia these days than in earlier years. This survival bias may cause underestimation of a declining trend in the incidence of dementia.

\section{All-cause dementia as a primary outcome measure}

Distinguishing clinical AD from other dementia subtypes such as vascular dementia or dementia with Lewy bodies has proven challenging in light of the multiple pathologies co-occurring with increased age in the majority of cases with dementia [23-26]. This is particularly troubling as the incidence of dementia increases steeply with age, with the vast majority of dementia cases occurring after 70 years of age. Studies of dementia and sporadic AD focused on older aged samples consequently recruit individuals in whom a large number of factors (e.g. neurodegenerative and vascular) contribute to cognitive decline and dementia, hampering accurate diagnosis of dementia subtypes. Not only does this burden etiological research, it could also contribute to heterogeneity in dementia diagnoses between cohorts. In addition, diagnosis of all-cause dementia is less susceptible to changes in clinical subtyping of dementia that may have occurred over time. For these reasons, the focus of the analysis is on all-cause dementia, which can be more reliably defined across cohorts. The wide age range of the unselected populations guarantees generalizability to understudied elderly individuals, and reflects the full spectrum of the dementia burden in the population.

\section{Dementia occurrence across cohorts}

Despite many similarities in design and data collection between the cohorts in this collaboration, there are also factors that may lead to differences in baseline incidence rates across the different cohorts. These include underlying population traits (e.g. access to health care, socioeconomic status, genetic make-up, and lifestyle), and variations in methodology (e.g. re-examination interval, continuous surveillance methods). For the most part these are likely to remain constant over the course of the study period, and although contributing to differences in baseline incidence, arguably less likely to influence within study trends. Differences in risk of mortality across cohorts, however, may differentially affect the results, because of survival bias, as described above. In addition, differences in the diagnosis of dementia across cohorts and region-specific changes in the clinical assessment of dementia over time pose a challenge to trend analysis. Lastly, all cohorts are embedded within the general population, but cannot completely avoid variation in sampling strategies and inclusion rates. Moreover, strategies for follow-up and disease surveillance vary, potentially affecting attrition or diagnostic sensitivity, which may hamper absolute risk estimates in particular.
Variation may, in part, be addressed by accounting for genetic heterogeneity, further stratification when sample size allows (e.g. for educational attainment, vascular disease burden), or use of more advanced statistical methods, such as illness-death modelling to deal with death occurring during the inter-examination interval.

Within the Alzheimer Cohorts Consortium nine prospective population-based cohort studies leverage conscientiously collected data over a 25 -year period with the aim to determine trends in the incidence of dementia and to unravel underlying causes. Uniting a wide range of diseasespecific and methodological expertise in research teams within and beyond these cohorts, the first analyses within the Alzheimer Cohorts Consortium are underway to tackle outstanding challenges in the assessment of time-trends in dementia occurrence.

Acknowledgements Investigators involved in the Alzheimer Cohorts Consortium collaboration include Roy Anderson, Alexa S. Beiser, Joshua C. Bis, Eric Boerwinkle, Carol Brayne, Daniel Bos, Lori B. Chibnik, Jean-François Dartigues, Sirwan K. Darweesh, Kendra Davis-Plourde, Stéphanie Debette, Carole Dufouil, Stephanie Evans, Myriam Fornage, Jaap Goudsmit, Leslie Grasset, Vilmundur Gudnason, Christoforos Hadjichrysanthou, Catherine Helmer, Jayandra J. Himali, Albert Hofman, M. Arfan Ikram, M. Kamran Ikram, Kevin McRae-McKee, Silke Kern, Lewis H. Kuller, Lenore J. Launer, Oscar L. Lopez, Fiona Matthews, Osorio Meirelles, Thomas H. Mosley Jr., Matthew P. Pase, Bruce M. Psaty, Claudia L. Satizabal, Sudha Seshadri, Ingmar Skoog, Blossom C.M. Stephan, Valter Sundh, Christophe Tzourio, Reem Waziry, Gerrit Jan Weverling, Mei Mei Wong, Frank de Wolf, Frank J. Wolters, and Anna Zettergren.

Funding The Alzheimer Cohorts Consortium is supported by an unrestricted grant from the Janssen Prevention Center to the Harvard T.H. Chan School of Public Health. Age, Gene/Environment Susceptibility (AGES) This study is supported by National Institute of Aging contracts (N01-AG-12100 and HHSN271201200022C) with contributions from the National Eye Institute, National Institute on Deafness and Other Communication Disorders, and the National Heart, Lung and Blood Institute, the National Institute of Aging Intramural Research Program, Hjartavernd (the Icelandic Heart Association), and the Althingi (the Icelandic Parliament); Atherosclerosis Risk in Communities (ARIC) This study is carried out as a collaborative study supported by National Heart, Lung, and Blood Institute contracts (HHSN268201100005C, HHSN2682011000 06C, HHSN268201100007C, HHSN268201100008C, HHSN2682011 00009C, HHSN268201100010C, HHSN268201100011C, and HHSN268201100012C). Neurocognitive data is collected by (U01 HL096812, HL096814, HL096899, HL096902, HL096917) with funding also provided by the National Institute of Neurologic Disorders and Stroke; Cardiovascular Health Study (CHS) This research was supported by contracts (HHSN268201200036C, HHSN268200800007C, N01HC55222, N01HC85079, N01HC85080, N01HC85081, N01HC85082, N01HC85083, N01HC85086), and grants U01HL080295, U01HL130114 and HL105756 from the National Heart, Lung, and Blood Institute (NHLBI), with additional contribution from the National Institute of Neurological Disorders and Stroke (NINDS). Additional support was provided by the National Institute on Aging (R01AG023629) and, in part, by grants (AG20098, AG15928, and AG05133). The funding sources did not have any role in the study design; collection, analysis, or interpretation of data; preparation of the manuscript; or decision to submit it for publication; 
Cognitive Function and Ageing Studies (CFAS) Medical Research Council (MRC) CFAS I was funded by the MRC (Research Grant: G9901400) and the National Health Service (NHS). CFAS II has been supported by the UK Medical Research Council (Research Grant:G06010220) and received additional support from the National Institute for Health Research (NIHR), comprehensive clinical research networks in West Anglia, Nottingham City and Nottinghamshire County NHS Primary Care trusts and the dementias and neurodegenerative disease research Network (DeNDRoN) in Newcastle; Framingham Heart Study (FHS) This work was supported by the National Heart, Lung, and Blood Institute's Framingham Heart Study (contracts N01-HC-25195 and HHSN268201500001I). This study was also supported by grants from the National Institute on Aging: (AG054076, U01-AG049505, and AG008122 (S. Seshadri)). S. Seshadri and A. Beiser were also supported by additional grants from the National Institute on Aging (R01AG049607, AG033193, AG033040) and the National Institute of Neurological Disorders and Stroke (R01-NS017950); The Gothenburg study This study was supported by grants from The Swedish Research Council 2012-5041, 2015-02830, 2013-8717, Swedish Research Council for Health, Working Life and Wellfare (no 2001-2646, 2003-0234, 2004-0150, 2006-0020, 2008-1229, 2012-1138, 2004-0145, 2006-0596, $2008-1111, \quad 2010-0870, \quad 2013-1202, \quad 2001-2849, \quad 2005-0762$, 2008-1210, 2013-2300, 013-2496, Konung Gustaf V:s och Drottning Victorias Frimurarestiftelse, Hjärnfonden, Sahlgrenska University Hospital (ALF), The Alzheimer's Association Zenith Award (ZEN01-3151), The Alzheimer's Association Stephanie B. Overstreet Scholars (IIRG-00-2159), Alzheimer's Association (IIRG-03-6168), The Alzheimer's Association (IIRG-09-131338), Eivind och Elsa K:son Sylvans stiftelse, Stiftelsen Söderström-Königska Sjukhemmet, Stiftelsen för Gamla Tjänarinnor, Handlanden Hjalmar Svenssons Forskningsfond, Stiftelsen Professor Bror Gadelius' Minnesfond, Swedish Alzheimer foundation; PAQUID The PAQUID cohort was supported by IPSEN France, NOVARTIS Pharma France, and the CNSA (Caisse Nationale de Solidarité et d'Autonomie). The research presented in this manuscript is original. The contents of this article are solely the responsibility of the authors. IPSEN, NOVARTIS and the CNSA did not fund this specific study. The funders had no role in the collection, management, analysis, or interpretation of the data and had no role in the preparation, review or approval of the manuscript; The Rotterdam Study This study is supported by the Erasmus Medical Centre and Erasmus University Rotterdam, The Netherlands Organization for Scientific Research (NWO), The Netherlands Organization for Health Research and Development (ZonMW), the Research Institute for Diseases in the Elderly (RIDE), The Netherlands Genomics Initiative, the Ministry of Education, Culture and Science, the Ministry of Health, Welfare and Sports, the European Commission (DG XII), and the Municipality of Rotterdam. Further support was obtained from the Netherlands Consortium for Healthy Ageing and the Dutch Heart Foundation (2012T008). This research was further supported by funding from the European Union Seventh Framework Program (FP7/2007e2013) under grant agreement no. 601055, VPHDare@IT (FP7-ICT-2011-9e601055); and funding from the European Union's Horizon 2020 research and innovation program under grant agreement no. 667375 (Co-STREAM) and under grant agreement no. 678543 (European Research Council (ERC) funded project: ORACLE). None of the funding organizations or sponsors were involved in study design, in collection, analysis, and interpretation of data, in writing of the report, or in the decision to submit the article for publication; The 3-Cites Study This study is conducted under a partnership agreement among the Institut National de la Santé et de la Recherche Médicale (INSERM), the Victor Segalen-Bordeaux II University, and Sanofi-Aventis. The Fondation pour la Recherche Médicale funded the preparation and initiation of the study. The 3C Study is also supported by the Caisse Nationale Maladie des Travailleurs Salariés, Direction Générale de la Santé, Mutuelle Générale de l'Education Nationale (MGEN), Institut de la Longévité, Conseils Régionaux of Aquitaine and Bourgogne, Fondation de France, and Ministry of Research-INSERM Programme "Cohortes et collections de données biologiques"; Infrastructure for the CHARGE Consortium is supported in part by National Heart, Lung and Blood Institute (HL105756) and for the neurology working group by National Institutes of Aging (AG033193 and AG049505).

Author contributions $\mathrm{LBC}, \mathrm{FJW}, \mathrm{AB}, \mathrm{JCB}, \mathrm{DB}, \mathrm{SKLD}, \mathrm{KLD}, \mathrm{CD}$, $\mathrm{MF}, \mathrm{CH}, \mathrm{CH}, \mathrm{LL}, \mathrm{FM}, \mathrm{OM}, \mathrm{AO}, \mathrm{CLS}, \mathrm{SS}, \mathrm{BS}, \mathrm{AH}$ contributed to designing the statistical analyses, LBC and FJW wrote the paper, $\mathrm{C}$ Berr, CB (Brayne), CD, MF, CH, MAI, LK, LL, TM, BMP, SS, IS, $\mathrm{AH}$ planned the study, and all authors reviewed and revised the manuscript.

\section{Compliance with ethical standards}

Conflict of interest Dr. Dartigues has a grant from Roche, Dr. Lopez is a consultant for Grifols, Lundbeck, and Raman Technologies and is supported by a National Institutes of Health Grant (P50 AG005133). Dr. Psaty serves on the DSMB of a clinical trial funded by Zoll LifeCor and on the Steering Committee of the Yale Open Data Access Project funded by Johnson \& Johnson. Dr Hofman is supported by an unrestricted grant from the Janssen Prevention Center. All other authors report no conflict of interests.

Open Access This article is distributed under the terms of the Creative Commons Attribution 4.0 International License (http://crea tivecommons.org/licenses/by/4.0/), which permits unrestricted use, distribution, and reproduction in any medium, provided you give appropriate credit to the original author(s) and the source, provide a link to the Creative Commons license, and indicate if changes were made.

\section{References}

1. Prince M, Bryce R, Albanese E, Wimo A, Ribeiro W, Ferri CP. The global prevalence of dementia: a systematic review and metaanalysis. Alzheimer's Dement J Alzheimer's Assoc. 2013;9(1):63-75.e2. doi:10.1016/j.jalz.2012.11.007.

2. International AsD: Policy brief for G8 heads of government. The global impact of Dementia 2013-2050. http://www.alz.co.uk/ research/G8-policy-brief (2013).

3. Hurd MD, Martorell P, Delavande A, Mullen KJ, Langa KM. Monetary costs of dementia in the United States. New Engl J Med. 2013;368(14):1326-34. doi:10.1056/NEJMsa1204629.

4. Grasset L, Brayne C, Joly P, Jacqmin-Gadda H, Peres K, FoubertSamier A, et al. Trends in dementia incidence: evolution over a 10-year period in France. Alzheimer's Dement J Alzheimer's Assoc. 2016;12(3):272-80. doi:10.1016/j.jalz.2015.11.001.

5. Matthews FE, Stephan BC, Robinson L, Jagger C, Barnes LE, Arthur A, et al. A two decade dementia incidence comparison from the Cognitive Function and Ageing Studies I and II. Nat Commun. 2016;7:11398. doi:10.1038/ncomms11398.

6. Rocca WA, Petersen RC, Knopman DS, Hebert LE, Evans DA, Hall KS, et al. Trends in the incidence and prevalence of Alzheimer's disease, dementia, and cognitive impairment in the United States. Alzheimer's Dement J Alzheimer's Assoc. 2011;7(1):80-93. doi:10.1016/j.jalz.2010.11.002.

7. Satizabal CL, Beiser AS, Chouraki V, Chene G, Dufouil C, Seshadri S. Incidence of Dementia over three decades in the Framingham Heart Study. New Engl J Med. 2016;374(6):523-32. doi:10.1056/NEJMoa1504327. 
8. Schrijvers EM, Verhaaren BF, Koudstaal PJ, Hofman A, Ikram MA, Breteler MM. Is dementia incidence declining? Trends in dementia incidence since 1990 in the Rotterdam study. Neurology. 2012;78(19):1456-63. doi:10.1212/WNL.0b013e3182 553 be6.

9. Li S, Yan F, Li G, Chen C, Zhang W, Liu J, et al. Is the dementia rate increasing in Beijing? Prevalence and incidence of dementia 10 years later in an urban elderly population. Acta Psychiatr Scand. 2007;115(1):73-9. doi:10.1111/j.1600-0447.2006.00859. $\mathrm{x}$.

10. Ohara T, Hata J, Yoshida D, Mukai N, Nagata M, Iwaki T, et al. Trends in dementia prevalence, incidence, and survival rate in a Japanese community. Neurology. 2017;88(20):1925-32. doi:10. 1212/WNL.0000000000003932.

11. Harris TB, Launer LJ, Eiriksdottir G, Kjartansson O, Jonsson PV, Sigurdsson G, et al. Age, Gene/Environment SusceptibilityReykjavik Study: multidisciplinary applied phenomics. Am J Epidemiol. 2007;165(9):1076-87.

12. Investigators TA. The Atherosclerosis Risk in Communities (ARIC) Study: design and objectives. The ARIC investigators. Am J Epidemiol. 1989;129(4):687-702. doi:10.1093/oxfordjour nals.aje.a115184.

13. Fried LP, Borhani NO, Enright P, Furberg CD, Gardin JM, Kronmal RA, et al. The Cardiovascular Health Study: design and rationale. Ann Epidemiol. 1991;1(3):263-76. doi:10.1016/10472797(91)90005-W.

14. Matthews FE, Arthur A, Barnes LE, Bond J, Jagger C, Robinson $\mathrm{L}$, et al. A two-decade comparison of prevalence of dementia in individuals aged 65 years and older from three geographical areas of England: results of the Cognitive Function and Ageing Study I and II. Lancet. 2013;382(9902):1405-12. doi:10.1016/S01406736(13)61570-6.

15. Dawber TR, Meadors GF, Moore FE Jr. Epidemiological approaches to heart disease: the Framingham study. Am J Public Health Nations Health. 1951;41(3):279-81. doi:10.2105/AJPH. 41.3.279.

16. Feinleib M, Kannel WB, Garrison RJ, McNamara PM, Castelli WP. The Framingham offspring study. Design and preliminary data. Prev Med. 1975;4(4):518-25. doi:10.1016/00917435(75)90035-3.

17. Splansky GL, Corey D, Yang Q, Atwood LD, Cupples LA, Benjamin EJ, et al. The third generation cohort of the National
Heart, Lung, and Blood Institute's Framingham Heart Study: design, recruitment, and initial examination. Am J Epidemiol. 2007;165(11):1328-35. doi:10.1093/aje/kwm021.

18. Bengtsson C, Blohme G, Hallberg L, Hallstrom T, Isaksson B, Korsan-Bengtsen $\mathrm{K}$, et al. The study of women in Gothenburg 1968-1969-a population study. General design, purpose and sampling results. Acta Med Scand. 1973;193(4):311-8. doi:10. 1111/j.0954-6820.1973.tb10583.x.

19. Dartigues JF, Gagnon M, Michel P, Letenneur L, Commenges D, Barberger-Gateau P, et al. The Paquid research program on the epidemiology of dementia. Methods and initial results. Rev Neurol. 1991;147(3):225-30.

20. Hofman A, Brusselle GG, Darwish Murad S, van Duijn CM, Franco OH, Goedegebure A, et al. The Rotterdam study: 2016 objectives and design update. Eur $\mathrm{J}$ Epidemiol. 2015;30(8):661-708. doi:10.1007/s10654-015-0082-x.

21. Group CS. Vascular factors and risk of dementia: design of the Three-City Study and baseline characteristics of the study population. Neuroepidemiology. 2003;22(6):316-25.

22. Lin D, Wei L. The Robust inference for the cox proportional hazards model. J Am Stat Assoc. 1989;84(408):1074-8. doi:10. 2307/2290085.

23. Wu YT, Beiser AS, Breteler MMB, Fratiglioni L, Helmer C, Hendrie $\mathrm{HC}$, et al. The changing prevalence and incidence of dementia over time-current evidence. Nat Rev Neurol. 2017;13(6):327-39. doi:10.1038/nrneurol.2017.63.

24. Winblad B, Amouyel P, Andrieu S, Ballard C, Brayne C, Brodaty $\mathrm{H}$, et al. Defeating Alzheimer's disease and other dementias: a priority for European science and society. Lancet Neurol. 2016;15(5):455-532. doi:10.1016/S1474-4422(16)00062-4.

25. Matthews FE, Brayne C, Lowe J, McKeith I, Wharton SB, Ince P. Epidemiological pathology of dementia: attributable-risks at death in the Medical Research Council Cognitive Function and Ageing Study. PLoS Med. 2009;6(11):e1000180. doi:10.1371/ journal.pmed.1000180.

26. Bennett DA, Wilson RS, Arvanitakis Z, Boyle PA, de ToledoMorrell L, Schneider JA. Selected findings from the Religious Orders Study and Rush Memory and Aging Project. J Alzheimers Dis JAD. 2013;33(Suppl 1):S397-403. doi:10.3233/JAD-2012129007. 